\title{
The 1986 CODATA Recommended Values Of the Fundamental Physical Constants
}

\author{
E. Richard Cohen \\ Rockwell International \\ Science Center \\ Thousand Oaks, CA 91360 \\ Barry N. Taylor \\ National Bureau of Standards \\ Gaithersburg, MD 20899
}

\begin{abstract}
This paper gives the values of the basic constants and conversion factors of physics and chemistry resulting from the 1986 least-squares adjustment of the fundamental physical constants as recently published by the CODATA Task Group on Fundamental Constants and as recommended for international use by CODATA. The new, 1986 CODATA set of recommended values replaces its predecessor pub-
\end{abstract}

lished by the Task Group and recommended for international use by CODATA in 1973.

Key words: CODATA; conversion factors; fundamental physical constants; least-squares adjustments; recommended values; Task Group on Fundamental Constants.

Accepted: January 14, 1987.
CODATA (Committee on Data for Science and Technology ${ }^{1}$ ) has recently published a report of the CODATA Task Group on Fundamental Constants prepared by the authors $[1]^{2}$ under the auspices and guidance of the Task Group. The report summarizes the 1986 least-squares adjustment of the fundamental physical constants and gives a set of self-consistent values for the basic constants and conversion factors of physics and chemistry derived from that adjustment. Recommended for international use by CODATA, this 1986 set of values is reprinted here for the convenience of the many readers of the Journal of Research of the $\mathrm{Na}$ tional Bureau of Standards and to assist in its dissemination throughout the scientific and technological communities. The 1986 CODATA set entirely replaces its immediate predecessor, that recommended for international use by CODATA in 1973. This set was based on the 1973 least-

\footnotetext{
'CODATA was established in 1966 as an interdisciplinary committee of the International Council of Scientific Unions. It seeks to improve the compilation, critical evaluation, storage, and retrieval of data of importance to science and technology. Dr. David R. Lide, chief of the NBS Office of Standard Reference Data, is the current President of CODATA.
}

${ }^{2}$ Figures in brackets indicate literature references. squares adjustment of the fundamental physical constants which was also carried out by the authors under the auspices and guidance of the Task Group [2,3].

As in previous least-squares adjustments of the constants $[3,4,5]$, the data for the 1986 adjustment were divided into two groups: auxiliary constants and stochastic input data. Examples of the 1986 auxiliary constants are the speed of light in vacuum $c \equiv 299792458 \mathrm{~m} / \mathrm{s}$; the permittivity of vacuum $\mu_{0} \equiv 4 \pi \times 10^{-7} \mathrm{~N} / \mathrm{A}^{2}$; the Rydberg constant for infinite mass $R_{\infty}$; and the quantity $E \equiv 483594.0 \times 10^{9}$ $\mathrm{Hz} / \mathrm{V}$ which is equal numerically to the value of the Josephson frequency-voltage ratio $2 e / h$ ( $e$ is the elementary charge and $h$ is the Planck constant) adopted in 1972 by the Consultative Committee on Electricity of the International Committee of

About the Authors: E. Richard Cohen is Distinguished Fellow, Rockwell International Science Center, and Barry N. Taylor is chief of the Electricity Division in the Center for Basic Standards, part of the NBS National Measurement Laboratory. Both Drs. Cohen and Taylor are physicists and members of the CODATA Task Group on Fundamental Constants. 
Weights and Measures for defining laboratory representations of the volt $[6,7]$. Quantities in this category are either defined constants such as $c, \mu_{0}$, and $E$ with no uncertainty, or constants such as $R_{\infty}$ with assigned uncertainties sufficiently small in comparison with the uncertainties assigned the stochastic input data with which they are associated in the adjustment that they can be taken as exact (i.e., their values are not subject to adjustment in contrast to the stochastic data). In the 1986 adjustment the uncertainty of each auxiliary constant was no greater than 0.02 parts-per-million or $\mathrm{ppm} .^{3}$ In contrast, the uncertainties assigned the 38 items of stochastic input data considered in the 1986 adjustment were in the range 0.065 to 9.7 ppm. (The 38 items were of 12 distinct types with the number of items of each type ranging from one to six.) Examples of such data are measurements of the proton gyromagnetic ratio $\gamma_{\mathrm{p}}^{\prime}$ (uncertainty in the range 0.24 to $5.4 \mathrm{ppm}$ ), the molar volume of silicon $M(\mathrm{Si}) / \rho(\mathrm{Si})(1.15 \mathrm{ppm})$, and the quantized Hall resistance $R_{\mathrm{H}}=h / e^{2}(0.12$ to $0.22 \mathrm{ppm})$.

Because new results which can influence a leastsquares adjustment of the constants are reported continually, it is always difficult to choose an optimal time at which to carry out a new adjustment and to revise the recommended values of the constants. In the present case, all data available up to 1 January 1986 were considered for inclusion, with the recognition that any additional changes to the 1973 recommended values that might result by taking into account more recent data would be much less than the changes resulting from the data available prior to that date.

Each of the 38 items of stochastic data are expressed (using the auxiliary constants as necessary) in terms of five quantities that serve as the "unknowns" or variables of the 1986 adjustment. These are $a^{-1}$, the inverse fine-structure constant; $K_{\mathrm{V}}$, a dimensionless quantity relating the SI (International System of Units) volt $\mathrm{V}$ to the unit of voltage $V_{76-B I}$ maintained at the International $\mathrm{Bu}$ reau of Weights and Measures (BIPM) using a value of the Josephson frequency-voltage ratio equal numerically to $E: \mathrm{V}_{76-\mathrm{BI}}=K_{\mathrm{V}} \mathrm{V}$, and thus $2 e / h=E / K_{\mathrm{V}} ; K_{\Omega}$, a dimensionless quantity relating the SI ohm to the BIPM as-maintained unit of resistance as it existed on 1 January $1985, \Omega_{\mathrm{Bl} 85}$, based on the mean resistance of a particular group of wire-wound precision resistors: $\Omega_{\mathrm{BI} 85}=K_{\Omega} \Omega$; $d_{220}$, the (220) lattice spacing of a perfect crystal of pure silicon at $22.5^{\circ} \mathrm{C}$ in vacuum; and $\mu_{\mu} / \mu_{p}$, the ratio of the magnetic moment of the muon to that

\footnotetext{
${ }^{3}$ Throughout, all uncertainties are one standard deviation estimates.
}

of the proton. "Best" values in the least-squares sense for these five quantities, with their variances and covariances, are thus the immediate output of the adjustment.

After a thorough analysis using a number of least-squares algorithms, the initial group of 38 items of stochastic input data was reduced to 22 items by deleting those that were either highly inconsistent with the remaining data or had assigned uncertainties so large that they carried negligible weight. The adjusted values of the five unknowns, and hence all the other 1986 recommended values that were subsequently derived from them (with the aid of the auxiliary constants), are therefore based on a least-squares adjustment with 17 degrees of freedom.

The 1986 adjustment represents a major advance over its 1973 counterpart; the uncertainties of the recommended values have been reduced by roughly an order of magnitude due to the enormous advances made throughout the precision measurement-fundamental constants field in the last dozen years. This can be seen from the following comparison of the 1973 and 1986 recommended values for the inverse fine-structure constant $\alpha^{-1}$, the elementary charge $e$, the Planck constant $h$, the electron mass $m_{\mathrm{e}}$, the Avogadro constant $N_{\mathrm{A}}$, the proton electron mass ratio $m_{\mathrm{p}} / m_{\mathrm{e}}$, the Faraday constant $F$, and the Josephson frequency-voltage ratio $2 e / h$ :

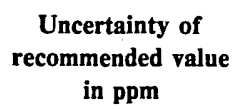

\begin{tabular}{lllc} 
Quantity & $\mathbf{1 9 7 3}$ & $\mathbf{1 9 8 6}$ & $\begin{array}{c}\text { resulting from } \\
\text { 1986 adjustment }\end{array}$ \\
\hline$\alpha^{-1}$ & 0.82 & 0.045 & -0.37 \\
$e$ & 2.9 & 0.30 & -7.4 \\
$h$ & 5.4 & 0.60 & -15.2 \\
$m_{\mathrm{e}}$ & 5.1 & 0.59 & -15.8 \\
$N_{\mathrm{A}}$ & 5.1 & 0.59 & +15.2 \\
$m_{\mathrm{p}} / m_{\mathrm{e}}$ & 0.38 & 0.020 & +0.64 \\
$F$ & 2.8 & 0.30 & +7.8 \\
$2 e / h$ & 2.6 & 0.30 & +7.8
\end{tabular}

It is also clear from this comparison that unexpectedly large changes have occurred in the 1973 recommended values of a number of these constants (i.e., a change which is large relative to the uncertainty assigned the 1973 value). These changes are a direct consequence of the $7.8 \mathrm{ppm}$ decrease from 1973 to 1986 in the quantity $K_{\mathrm{V}}$ and the high correlation between $K_{\mathrm{V}}$ and the calculated values of $e$, $h, m_{\mathrm{e}}, N_{\mathrm{A}}$, and $F$. Since $2 e / h=E / K_{\mathrm{V}}$, the 1986 value of $K_{\mathrm{V}}$ also implies that the value of the Josephson frequency-voltage ratio adopted by the Consultative Committee on Electricity in 1972, which was believed to be consistent with the SI value and which most national standards laborato- 
ries adopted to define and maintain their laboratory unit of voltage, is actually $7.8 \mathrm{ppm}$ smaller than the SI value. This unsatisfactory situation should be rectified in the near future $[8,9]$.

The large change in $K_{\mathrm{V}}$ and hence in many other quantities between 1973 and 1986 would have been avoided if two determinations of $F$ which seemed to be discrepant with the remaining data had not been deleted in the 1973 adjustment. In retrospect, the disagreement was comparatively mild. In view of this experience it is important to recognize that there are no similar disagreements in the 1986 adjustment; the measurements which were deleted were so discrepant that they obviously could not be correct, or of such low weight that if retained the adjusted values of the five unknowns would change negligibly. Thus, it is unlikely that any alternate evaluation of the data considered in the 1986 least-squares adjustment could lead to significant changes in the 1986 recommended values. Moreover, the quality of the 1986 data and its redundancy would seem to preclude future changes in the 1986 recommended values relative to their uncertainties comparable to the changes which occurred in the 1973 values.

The 1986 recommended values of the fundamental physical constants are given in five tables. Table 1 is an abbreviated list containing the quantities which should be of greatest interest to most users. Table 2 is a much more complete compilation.

Table 1. Summary of the 1986 recommended values of the fundamental physical constants.

An abbreviated list of the fundamental constants of physics and chemistry based on a least-squares adjustment with 17 degrees of freedom. The digits in parentheses are the one-standard-deviation uncertainty in the last digits of the given value. Since the uncertainties of many of these entries are correlated, the full covariance matrix must be used in evaluating the uncertainties of quantities computed from them.

\section{Quantity}

speed of light in vacuum

permeability of vacuum

permittivity of vacuum

Newtonian constant of gravitation

Planck constant

$$
h / 2 \pi
$$

elementary charge

magnetic flux quantum, $h / 2 e$

electron mass

proton mass

proton-electron mass ratio

fine-structure constant, $\mu_{0} c e^{2} / 2 h$

inverse fine-structure constant

Rydberg constant, $m_{\mathrm{e}} c \alpha^{2} / 2 h$

Avogadro constant

Faraday constant, $N_{\mathrm{A}} e$

molar gas constant

Boltzmann constant, $R / N_{\mathrm{A}}$

Stefan-Boltzmann constant,

$$
\left(\pi^{2} / 60\right) k^{4} / \hbar^{3} c^{2}
$$

electron volt, $(e / C) \mathrm{J}=\{e\} \mathrm{J}$

(unified) atomic mass unit,

$$
1 \mathrm{u}=m_{\mathrm{u}}=\frac{1}{12} m\left({ }^{12} \mathrm{C}\right)
$$

Relative

Uncertainty

Symbol Value

Units

(ppm)

$\begin{array}{llll}c & 299792458 & \mathrm{~m} \mathrm{~s}^{-1} & \text { (exact) } \\ \mu_{\circ} & 4 \pi \times 10^{-7} & \mathrm{~N} \mathrm{~A}^{-2} & \\ & =12.566370614 \ldots & 10^{-7} \mathrm{~N} \mathrm{~A}^{-2} & \text { (exact) } \\ \epsilon_{\mathrm{o}} & 1 / \mu_{\mathrm{o}} c^{2} & & \\ & = & & \\ G & 6.654187817 \ldots & 10^{-12} \mathrm{~F} \mathrm{~m}^{-1} & \text { (exact) } \\ h & 6.6260755(40) & 10^{-34} \mathrm{~J} \mathrm{~s}^{3} \mathrm{~kg}^{-1} \mathrm{~s}^{-2} & 128 \\ \hbar & 1.05457266(63) & 10^{-34} \mathrm{~J} \mathrm{~s} & 0.60 \\ e & 1.60217733(49) & 10^{-19} \mathrm{C} & 0.60 \\ \Phi_{\mathrm{o}} & 2.06783461(61) & 10^{-15} \mathrm{~Wb} & 0.30 \\ m_{\mathrm{e}} & 9.1093897(54) & 10^{-31} \mathrm{~kg}^{-27} & 0.30 \\ m_{\mathrm{p}} & 1.6726231(10) & 10^{-27} \mathrm{~kg} & 0.59 \\ m_{\mathrm{p}} / m_{\mathrm{e}} & 1836.152701(37) & & 0.59 \\ \alpha & 7.29735308(33) & 10^{-3} & 0.020 \\ \alpha & 137.0359895(61) & & 0.045 \\ R_{\infty} & 10973731.534(13) & \mathrm{m}^{-1} & 0.045 \\ N_{\mathrm{A}}, L & 6.0221367(36) & 10^{23} \mathrm{~mol}^{-1} & 0.0012 \\ F & 96485.309(29) & \mathrm{C} \mathrm{mol}^{-1} & 0.59 \\ R & 8.314510(70) & \mathrm{J} \mathrm{mol}^{-1} \mathrm{~K}^{-1} & 0.30 \\ k & 1.380658(12) & 10^{-23} \mathrm{~J} \mathrm{~K}^{-1} & 8.4 \\ \sigma & 5.67051(19) & 10^{-8} \mathrm{~W} \mathrm{~m}^{-2} \mathrm{~K}^{-4} & 34\end{array}$

Non-SI units used with SI

$\begin{array}{llll}\mathrm{eV} & 1.60217733(49) & 10^{-19} \mathrm{~J} & 0.30 \\ \mathrm{u} & 1.6605402(10) & 10^{-27} \mathrm{~kg} & 0.59\end{array}$




\section{Journal of Research of the National Bureau of Standards}

Table 2. The 1986 recommended values of the fundamental physical constants.

This list of the fundamental constants of physics and chemistry is based on a least-squares adjustment with 17 degrees of freedom. The digits in parentheses are the one-standard-deviation uncertainty in the last digits of the given value. Since the uncertainties of many of these entries are correlated, the full covariance matrix must be used in evaluating the uncertainties of quantities computed from them.

\section{GENERAL CONSTANTS}

\section{Universal Constants}

speed of light in vacuum

permeability of vacuum

$\begin{array}{llll}c & 299792458 & \mathrm{~m} \mathrm{~s}^{-1} & \text { (exact) } \\ \mu_{\mathrm{o}} & 4 \pi \times 10^{-7} & \mathrm{~N} \mathrm{~A}^{-2} & \\ & =12.566370614 \ldots & 10^{-7} \mathrm{~N} \mathrm{~A}^{-2} & \text { (exact) } \\ \epsilon_{\mathrm{o}} & 1 / \mu_{\mathrm{o}} c^{2} & & \\ & =8.854187817 \ldots & 10^{-12} \mathrm{~F} \mathrm{~m}^{-1} & \text { (exact) } \\ G & 6.67259(85) & 10^{-11} \mathrm{~m}^{3} \mathrm{~kg}^{-1} \mathrm{~s}^{-2} & 128 \\ h & 6.6260755(40) & 10^{-34} \mathrm{~J} \mathrm{~s}^{-130} & 0.60 \\ & 4.1356692(12) & 10^{-15} \mathrm{eV} \mathrm{s} & 0.30 \\ \hbar & 1.05457266(63) & 10^{-34} \mathrm{~J} \mathrm{~s} & 0.60 \\ & 6.5821220(20) & 10^{-16} \mathrm{eV} \mathrm{s} & 0.30 \\ m_{\mathrm{P}} & 2.17671(14) & 10^{-8} \mathrm{~kg} & 64 \\ l_{\mathrm{P}} & 1.61605(10) & 10^{-35} \mathrm{~m} & 64 \\ t_{\mathrm{P}} & 5.39056(34) & 10^{-44} \mathrm{~s} & 64\end{array}$

Electromagnetic Constants

elementary charge

magnetic flux quantum, $h / 2 e$ Josephson frequency-voltage ratio quantized Hall conductance quantized Hall resistance,

$$
h / e^{2}=\mu_{0} c / 2 \alpha
$$

Bohr magneton, $e \hbar / 2 m_{\mathrm{e}}$

in electron volts, $\mu_{\mathrm{B}} /\{e\}$

in hertz, $\mu_{\mathrm{B}} / \mathrm{h}$

in wavenumbers, $\mu_{\mathrm{B}} / h c$

in kelvins, $\mu_{\mathrm{B}} / k$

nuclear magneton, $e \hbar / 2 m_{\mathrm{p}}$

in electron volts, $\mu_{\mathrm{N}} /\{e\}$

in hertz, $\mu_{\mathrm{N}} / h$

in wavenumbers, $\mu_{\mathrm{N}} / h c$

in kelvins, $\mu_{\mathrm{N}} / k$

$\begin{array}{llll}e & 1.60217733(49) & 10^{-19} \mathrm{C}^{14} & 0.30 \\ e / h & 2.41798836(72) & 10^{14} \mathrm{~A} \mathrm{~J}^{-1} & 0.30 \\ \Phi_{\circ} & 2.06783461(61) & 10^{-15} \mathrm{~Wb} & 0.30 \\ 2 e / h & 4.8359767(14) & 10^{14} \mathrm{~Hz} \mathrm{~V}^{-1} & 0.30 \\ e^{2} / h & 3.87404614(17) & 10^{-5} \mathrm{~S} & 0.045 \\ R_{\mathrm{H}} & 25812.8056(12) & \Omega & 0.045 \\ & & & \\ \mu_{\mathrm{B}} & 9.2740154(31) & 10^{-24} \mathrm{~J} \mathrm{~T}^{-1} & 0.34 \\ & 5.78838263(52) & 10^{-5} \mathrm{eV} \mathrm{T}^{-1} & 0.089 \\ & 1.39962418(42) & 10^{10} \mathrm{~Hz} \mathrm{~T}^{-1} & 0.30 \\ & 46.686437(14) & \mathrm{m}^{-1} \mathrm{~T}^{-1} & 0.30 \\ \mu_{\mathrm{N}} & 0.6717099(57) & \mathrm{K} \mathrm{T}^{-1} & 8.5 \\ & 5.0507866(17) & 10^{-27} \mathrm{~J} \mathrm{~T}^{-1} & 0.34 \\ & 3.15245166(28) & 10^{-8} \mathrm{eV} \mathrm{T}^{-1} & 0.089 \\ & 7.6225914(23) & \mathrm{MHz} \mathrm{T}^{-1} & 0.30 \\ & 2.54262281(77) & 10^{-2} \mathrm{~m}^{-1} \mathrm{~T}^{-1} & 0.30 \\ & 3.658246(31) & 10^{-4} \mathrm{~K} \mathrm{~T}^{-1} & 8.5\end{array}$


Table 2. The 1986 recommended values of the fundamental physical constants (continued).

Relative

Uncertainty

Quantity

Symbol

Value

Units

(ppm)

\section{ATOMIC CONSTANTS}

fine-structure constant, $\mu_{0} c e^{2} / 2 h$ inverse fine-structure constant

Rydberg constant, $m_{\mathrm{e}} c \alpha^{2} / 2 h$ in hertz, $R_{\infty} c$ in joules, $R_{\infty} h c$ in $\mathrm{eV}, R_{\infty} h c /\{e\}$

Bohr radius, $\alpha / 4 \pi R_{\infty}$

Hartree energy, $e^{2} / 4 \pi \epsilon_{0} a_{0}=2 R_{\infty} h c$ in $\mathrm{eV}, E_{\mathrm{h}} /\{e\}$

quantum of circulation

electron mass

in electron volts, $m_{\mathrm{e}} c^{2} /\{e\}$

electron-muon mass ratio

electron-proton mass ratio

electron-deuteron mass ratio

electron- $\alpha$-particle mass ratio

electron specific charge

electron molar mass

Compton wavelength, $h / m_{\mathrm{e}} c$ $\lambda_{\mathrm{C}} / 2 \pi=\alpha a_{\mathrm{o}}=\alpha^{2} / 4 \pi R_{\infty}$

classical electron radius, $\alpha^{2} a_{0}$

Thomson cross section, $(8 \pi / 3) r_{\mathrm{e}}^{2}$

electron magnetic moment

in Bohr magnetons

in nuclear magnetons

electron magnetic moment anomaly, $\mu_{\mathrm{e}} / \mu_{\mathrm{B}}-1$

electron g-factor, $2\left(1+a_{\mathrm{e}}\right)$

electron-muon

magnetic moment ratio

electron-proton

magnetic moment ratio

muon mass

in electron volts, $m_{\mu} c^{2} /\{e\}$

muon-electron mass ratio

muon molar mass

muon magnetic moment

in Bohr magnetons,

in nuclear magnetons,

$\begin{array}{llll}\alpha & 7.29735308(33) & 10^{-3} & 0.045 \\ \alpha^{-1} & 137.0359895(61) & & 0.045 \\ R_{\infty} & 10973731.534(13) & \mathrm{m}^{-1} & 0.0012 \\ & 3.2898419499(39) & 10^{15} \mathrm{~Hz} & 0.0012 \\ & 2.1798741(13) & 10^{-18} \mathrm{~J} & 0.60 \\ & 13.6056981(40) & \mathrm{eV} & 0.30 \\ a_{\circ} & 0.529177249(24) & 10^{-10} \mathrm{~m} & 0.045 \\ E_{\mathrm{h}} & 4.3597482(26) & 10^{-18} \mathrm{~J} & 0.60 \\ & 27.2113961(81) & \mathrm{eV} & 0.30 \\ h / 2 m_{\mathrm{e}} & 3.63694807(33) & 10^{-4} \mathrm{~m}^{2} \mathrm{~s}^{-1} & 0.089 \\ h / m_{\mathrm{e}} & 7.27389614(65) & 10^{-4} \mathrm{~m}^{2} \mathrm{~s}^{-1} & 0.089\end{array}$

Electron

\begin{tabular}{|c|c|c|c|}
\hline \multirow[t]{3}{*}{$m_{\mathrm{e}}$} & $9.1093897(54)$ & $10^{-31} \mathrm{~kg}$ & 0.59 \\
\hline & $5.48579903(13)$ & $10^{-4} \mathrm{u}$ & 0.023 \\
\hline & $0.51099906(15)$ & $\mathrm{MeV}$ & 0.30 \\
\hline$m_{\mathrm{e}} / m_{\mu}$ & $4.83633218(71)$ & $10^{-3}$ & 0.15 \\
\hline$m_{\mathrm{e}} / m_{\mathrm{p}}$ & $5.44617013(11)$ & $10^{-4}$ & 0.020 \\
\hline$m_{\mathrm{e}} / m_{\mathrm{d}}$ & $2.72443707(6)$ & $10^{-4}$ & 0.020 \\
\hline$m_{\mathrm{e}} / m_{\alpha}$ & $1.37093354(3)$ & $10^{-4}$ & 0.021 \\
\hline$-e / m_{\mathrm{e}}$ & $-1.75881962(53)$ & $10^{11} \mathrm{C} \mathrm{kg}^{-1}$ & 0.30 \\
\hline$M(\mathrm{e}), M_{\mathrm{e}}$ & $5.48579903(13)$ & $10^{-7} \mathrm{~kg} / \mathrm{mol}$ & 0.023 \\
\hline$\lambda_{\mathrm{C}}$ & $2.42631058(22)$ & $10^{-12} \mathrm{~m}$ & 0.089 \\
\hline$\lambda_{\mathrm{C}}$ & $3.86159323(35)$ & $10^{-13} \mathrm{~m}$ & 0.089 \\
\hline$r_{\mathrm{e}}$ & $2.81794092(38)$ & $10^{-15} \mathrm{~m}$ & 0.13 \\
\hline$\sigma_{\mathrm{e}}$ & $0.66524616(18)$ & $10^{-28} \mathrm{~m}^{2}$ & 0.27 \\
\hline$\mu_{\mathrm{e}}$ & $928.47701(31)$ & $10^{-26} \mathrm{~J} \mathrm{~T}^{-1}$ & 0.34 \\
\hline$\mu_{\mathrm{e}} / \mu_{\mathrm{B}}$ & $1.001159652193(10)$ & & $1 \times 10^{-5}$ \\
\hline$\mu_{\mathrm{e}} / \mu_{\mathrm{N}}$ & $1838.282000(37)$ & & 0.020 \\
\hline$a_{\mathrm{e}}$ & $1.159652193(10)$ & $10^{-3}$ & 0.0086 \\
\hline$g_{\mathrm{e}}$ & $2.002319304386(20)$ & & $1 \times 10^{-5}$ \\
\hline$\mu_{\mathrm{e}} / \mu_{\mu}$ & $206.766967(30)$ & & 0.15 \\
\hline$\mu_{\mathrm{e}} / \mu_{\mathrm{p}}$ & $658.2106881(66)$ & & 0.010 \\
\hline \multicolumn{4}{|c|}{ Muon } \\
\hline \multirow[t]{3}{*}{$m_{\mu}$} & $1.8835327(11)$ & $10^{-28} \mathrm{~kg}$ & 0.61 \\
\hline & $0.113428913(17)$ & $\mathrm{u}$ & 0.15 \\
\hline & $105.658389(34)$ & $\mathrm{MeV}$ & 0.32 \\
\hline$m_{\mu} / m_{\mathrm{e}}$ & $206.768262(30)$ & & 0.15 \\
\hline$M(\mu), M_{\mu}$ & $1.13428913(17)$ & $10^{-4} \mathrm{~kg} / \mathrm{mol}$ & 0.15 \\
\hline$\mu_{\mu}$ & $4.4904514(15)$ & $10^{-26} \mathrm{~J} \mathrm{~T}^{-1}$ & 0.33 \\
\hline$\mu_{\mu} / \mu_{\mathrm{B}}$ & $4.84197097(71)$ & $10^{-3}$ & 0.15 \\
\hline$\mu_{\mu} / \mu_{N}$ & $8.8905981(13)$ & & 0.15 \\
\hline
\end{tabular}


Table 2. The 1986 recommended values of the fundamental physical constants (continued).

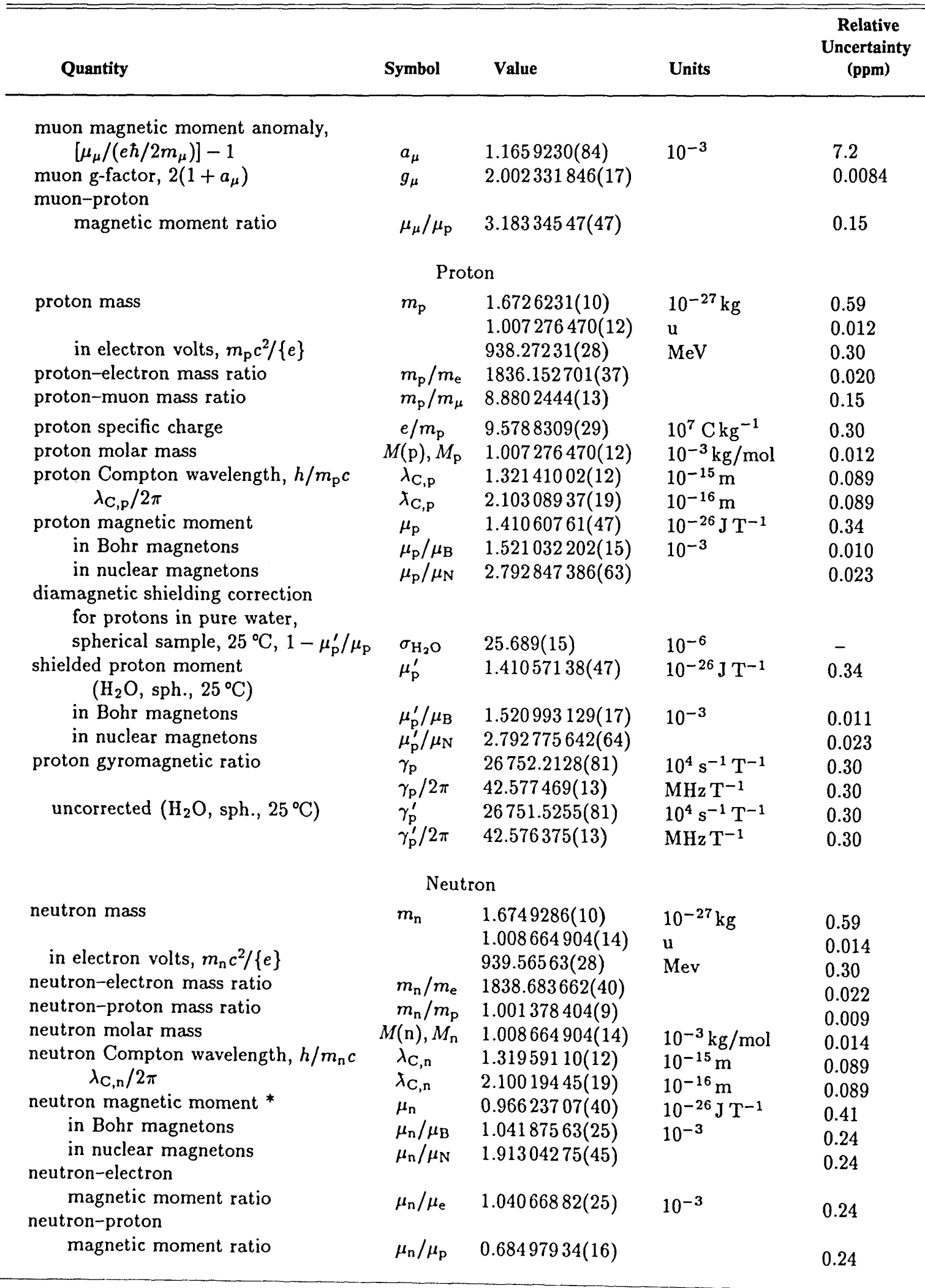


Table 2. The 1986 recommended values of the fundamental physical constants (continued).

\begin{tabular}{|c|c|c|c|c|}
\hline Quantity & Symbol & Value & Units & $\begin{array}{r}\text { Relativ } \\
\text { Uncertai } \\
\text { (ppm) }\end{array}$ \\
\hline \multicolumn{5}{|c|}{ Deuteron } \\
\hline deuteron mass & $m_{\mathrm{d}}$ & $\begin{array}{l}3.3435860(20) \\
2.013553214(24)\end{array}$ & $\begin{array}{l}10^{-27} \mathrm{~kg} \\
\mathrm{u}\end{array}$ & $\begin{array}{l}0.59 \\
0.012\end{array}$ \\
\hline in electron volts, $m_{\mathrm{d}} c^{2} /\{e\}$ & & $1875.61339(57)$ & $\mathrm{MeV}$ & 0.30 \\
\hline deuteron-electron mass ratio & $m_{\mathrm{d}} / m_{\mathrm{e}}$ & $3670.483014(75)$ & & 0.020 \\
\hline deuteron-proton mass ratio & $m_{\mathrm{d}} / m_{\mathrm{p}}$ & $1.999007496(6)$ & & 0.003 \\
\hline deuteron molar mass & $M(\mathrm{~d}), M_{\mathrm{d}}$ & $2.013553214(24)$ & $10^{-3} \mathrm{~kg} / \mathrm{mol}$ & 0.012 \\
\hline deuteron magnetic moment $*$ & $\mu_{\mathrm{d}}$ & $0.43307375(15)$ & $10^{-26} \mathrm{~J} \mathrm{~T}^{-1}$ & 0.34 \\
\hline in Bohr magnetons, & $\mu_{\mathrm{d}} / \mu_{\mathrm{B}}$ & $0.4669754479(91)$ & $10^{-3}$ & 0.019 \\
\hline $\begin{array}{l}\text { in nuclear magnetons, } \\
\text { deuteron-electron }\end{array}$ & $\mu_{\mathrm{d}} / \mu_{\mathrm{N}}$ & $0.857438230(24)$ & & 0.028 \\
\hline $\begin{array}{l}\text { magnetic moment ratio } \\
\text { deuteron-proton }\end{array}$ & $\mu_{\mathrm{d}} / \mu_{\mathrm{e}}$ & $0.4664345460(91)$ & $10^{-3}$ & 0.019 \\
\hline magnetic moment ratio & $\mu_{\mathrm{d}} / \mu_{\mathrm{p}}$ & $0.3070122035(51)$ & & 0.017 \\
\hline
\end{tabular}

\section{PHYSICO-CHEMICAL CONSTANTS}

\section{Avogadro constant}

atomic mass constant, $\frac{1}{12} m\left({ }^{12} \mathrm{C}\right)$

in electron volts, $m_{\mathrm{u}} c^{2} /\{e\}$

Faraday constant

molar Planck constant

molar gas constant

Boltzmann constant, $R / N_{\mathrm{A}}$ in electron volts, $k /\{e\}$

in hertz, $k / h$

in wavenumbers, $k / h c$

molar volume (ideal gas), $R T / p$

$$
\begin{gathered}
T=273.15 \mathrm{~K}, \quad p=101325 \mathrm{~Pa} \\
\text { Loschmidt constant, } N_{\mathrm{A}} / V_{\mathrm{m}} \\
T=273.15 \mathrm{~K}, \quad p=100 \mathrm{kPa}
\end{gathered}
$$

Sackur-Tetrode constant

$$
\begin{gathered}
\text { (absolute entropy constant), } \\
\frac{5}{2}+\ln \left\{\left(2 \pi m_{\mathrm{u}} k T_{1} / h^{2}\right)^{\frac{3}{2}} k T_{1} / p_{\mathrm{o}}\right\} \\
T_{1}=1 \mathrm{~K}, \quad p_{0}=100 \mathrm{kPa} \\
\quad p_{0}=101325 \mathrm{~Pa}
\end{gathered}
$$

Stefan-Boltzmann constant,

$$
\left(\pi^{2} / 60\right) k^{4} / \hbar^{3} c^{2}
$$

first radiation constant, $2 \pi h c^{2}$

second radiation constant, $h c / k$

Wien displacement law constant,

$$
b=\lambda_{\max } T=c_{2} / 4.96511423 \ldots
$$

$N_{\mathrm{A}}, L$
$m_{\mathrm{u}}$
$F$
$N_{\mathrm{A}} h$
$N_{\mathrm{A}} h c$
$R$
$k$

\section{$S_{0} / R$}

$$
-1.151693(21)
$$$$
-1.164856(21)
$$

$6.0221367(36)$
$1.6605402(10)$

931.49432(28)

$96485.309(29)$

$3.99031323(36)$

$0.11962658(11)$

$8.314510(70)$

$1.380658(12)$

$8.617385(73)$

$2.083674(18)$

$69.50387(59)$

$\begin{array}{ll}V_{\mathrm{m}} & 22.41410(19) \\ n_{\circ} & 2.686763(23) \\ V_{\mathrm{m}} & 22.71108(19)\end{array}$

$5.67051(19)$

$3.7417749(22)$

$0.01438769(12)$

$2.897756(24)$
$10^{23} \mathrm{~mol}^{-1}$
$10^{-27} \mathrm{~kg}$
$\mathrm{MeV}$

0.59

0.59

$\mathrm{Cmol}^{-1}$

0.30

$10^{-10} \mathrm{~J} \mathrm{~s} \mathrm{~mol}^{-1}$

0.30

$\mathrm{J} \mathrm{m} \mathrm{mol}{ }^{-1}$

$\mathrm{J} \mathrm{mol}^{-1} \mathrm{~K}^{-1}$

$10^{-23} \mathrm{~J} \mathrm{~K}^{-1}$

$10^{-5} \mathrm{eV} \mathrm{K}^{-1}$

$10^{10} \mathrm{~Hz} \mathrm{~K}^{-1}$

$\mathrm{m}^{-1} \mathrm{~K}^{-1}$

0.089

0.089

8.4

8.5

8.4

8.4

8.4

$\mathrm{L} / \mathrm{mol}$

8.4

$10^{25} \mathrm{~m}^{-3}$

8.5

$\mathrm{L} / \mathrm{mol}$

8.4

*The scalar magnitude of the neutron moment is listed here. The neutron magnetic dipole is directed oppositely to that of the proton, and corresponds to the dipole associated with a spinning negative charge distribution. The vector sum, $\mu_{d}=\mu_{p}+\mu_{n}$, is approximately satisfied.

**The entropy of an ideal monatomic gas of relative atomic weight $A_{\mathrm{r}}$ is given by $S=S_{\mathrm{o}}+\frac{3}{2} R \ln A_{\mathrm{r}}-R \ln \left(p / p_{\mathrm{o}}\right)+\frac{5}{2} R \ln (T / \mathrm{K})$. 
Table 3 is a list of related "maintained units and standard values," while table 4 contains a number of scientifically, technologically, and metrologically useful energy conversion factors. Finally, table 5 is an extended covariance matrix containing the variances, covariances, and correlation coefficients of the unknowns and a number of different constants (included for convenience) from which the like quantities for other constants may be readily calculated. ${ }^{4}$ Such a matrix is necessary, of course, because the variables in a least-squares adjustment are statistically correlated. Thus, with the exception of quantities which depend only on aux-

${ }^{4}$ The variable $d_{220}$ is omitted from table 5 because there is little need for its correlations with other quantities. Moreover, since the more significant and related quantity $N_{\mathrm{A}}$ is included (note that $N_{\mathrm{A}} \sim d_{220}^{-3}$ ), there is no loss of information by omitting $d_{220}$.

Table 3. Maintained units and standard values.

A summary of "maintained" units and "standard" values and their relationship to SI units, based on a leastsquares adjustment with 17 degrees of freedom. The digits in parentheses are the one-standard-deviation uncertainty in the last digits of the given value. Since the uncertainties of many of these entries are correlated, the full covariance matrix must be used in evaluating the uncertainties of quantities computed from them.

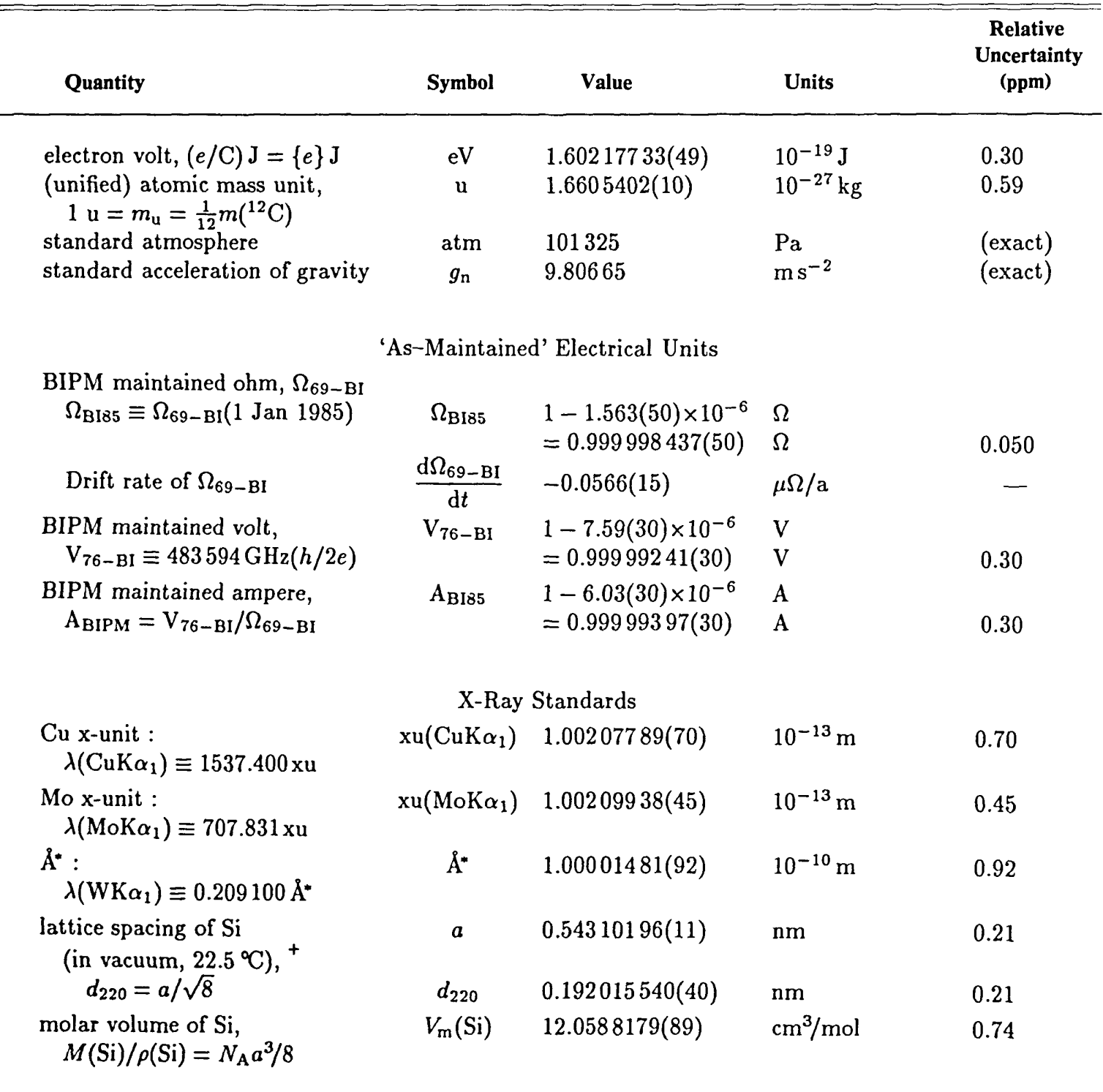

+ The lattice spacing of single-crystal Si can vary by parts in $10^{7}$ depending on the preparation process. Measurements at PTB indicate also the possibility of distortions from exact cubic symmetry of the order of $0.2 \mathrm{ppm}$. 
iliary constants, the uncertainty associated with a quantity calculated from other constants in general can be found only with the use of the full covariance matrix.

To use table 5, note that the covariance between two quantities $Q_{k}$ and $Q_{s}$ which are functions of a common set of variables $x_{i}(i=1, \ldots, N)$ is given by

$$
v_{k s}=\sum_{i, j=1}^{N} \frac{\partial Q_{k}}{\partial x_{i}} \frac{\partial Q_{s}}{\partial x_{j}} v_{i j}
$$

where $v_{i j}$ is the covariance of $x_{i}$ and $x_{j}$. In this general form, the units of $v_{i j}$ are the product of the units of $x_{i}$ and $x_{j}$ and the units of $v_{k s}$ are the product of the units of $Q_{k}$ and $Q_{s}$. For most cases of interest

Table 4. Energy conversion factors.

To use this table note that all entries on the same line are equal; the unit at the top of a column applies to all of the values beneath it.

Example: $1 \mathrm{eV}=806544.10 \mathrm{~m}^{-1}$

\begin{tabular}{|c|c|c|c|c|}
\hline & $\mathbf{J}$ & kg & $m^{-1}$ & $\mathbf{H z}$ \\
\hline $1 \mathrm{~J}=$ & 1 & $\begin{array}{l}1 /\left\{c^{2}\right\} \\
1.11265006 \times 10^{-17}\end{array}$ & $\begin{array}{l}1 /\{h c\} \\
5.0341125(30) \times 10^{24}\end{array}$ & $\begin{array}{l}1 /\{h\} \\
1.50918897(90) \times 10^{33}\end{array}$ \\
\hline $1 \mathrm{~kg}=$ & $\begin{array}{l}\left\{c^{2}\right\} \\
8.987551787 \times 10^{16}\end{array}$ & 1 & $\begin{array}{l}\{c / h\} \\
4.5244347(27) \times 10^{41}\end{array}$ & $\begin{array}{l}\left\{c^{2} / h\right\} \\
1.35639140(81) \times 10^{50}\end{array}$ \\
\hline $1 \mathrm{~m}^{-1}=$ & $\begin{array}{l}\{h c\} \\
1.9864475(12) \times 10^{-25}\end{array}$ & $\begin{array}{l}\{h / c\} \\
2.2102209(13) \times 10^{-42}\end{array}$ & 1 & $\begin{array}{l}\{c\} \\
299792458\end{array}$ \\
\hline $1 \mathrm{~Hz}=$ & $\begin{array}{l}\{h\} \\
6.6260755(40) \times 10^{-34}\end{array}$ & $\begin{array}{l}\left\{h / c^{2}\right\} \\
7.3725032(44) \times 10^{-51}\end{array}$ & $\begin{array}{l}1 /\{c\} \\
3.335640952 \times 10^{-9}\end{array}$ & 1 \\
\hline $1 \mathrm{~K}=$ & $\begin{array}{l}\{k\} \\
1.380658(12) \times 10^{-23}\end{array}$ & $\begin{array}{l}\left\{k / c^{2}\right\} \\
1.536189(13) \times 10^{-40}\end{array}$ & $\begin{array}{l}\{k / h c\} \\
69.50387(59)\end{array}$ & $\begin{array}{l}\{k / h\} \\
2.083674(18) \times 10^{10}\end{array}$ \\
\hline $1 \mathrm{eV}=$ & $\begin{array}{l}\{e\} \\
1.60217733(49) \times 10^{-19}\end{array}$ & $\begin{array}{l}\left\{e / c^{2}\right\} \\
1.78266270(54) \times 10^{-36}\end{array}$ & $\begin{array}{l}\{e / h c\} \\
806554.10(24)\end{array}$ & $\begin{array}{l}\{e / h\} \\
2.41798836(72) \times 10^{14}\end{array}$ \\
\hline $1 \mathrm{u}=$ & $\begin{array}{l}\left\{m_{\mathrm{u}} c^{2}\right\} \\
1.49241909(88) \times 10^{-10}\end{array}$ & $\begin{array}{l}\left\{m_{\mathrm{u}}\right\} \\
1.6605402(10) \times 10^{-27}\end{array}$ & $\begin{array}{l}\left\{m_{\mathrm{u}} c / h\right\} \\
7.51300563(67) \times 10^{14}\end{array}$ & $\begin{array}{l}\left\{m_{\mathrm{u}} c^{2} / h\right\} \\
2.25234242(20) \times 10^{23}\end{array}$ \\
\hline hartree $=$ & $\begin{array}{l}\left\{2 R_{\infty} h c\right\} \\
4.3597482(26) \times 10^{-18}\end{array}$ & $\begin{array}{l}\left\{2 R_{\infty} h / c\right\} \\
4.8508741(29) \times 10^{-35}\end{array}$ & $\begin{array}{l}\left\{2 R_{\infty}\right\} \\
21947463.067(26)\end{array}$ & $\begin{array}{l}\left\{2 R_{\infty} c\right\} \\
6.5796838999(78) \times 10^{15}\end{array}$ \\
\hline
\end{tabular}

$\mathbf{K}$

eV

$\mathbf{u}$

hartree

\begin{tabular}{|c|c|c|c|c|}
\hline $1 \mathrm{~J}=$ & $\begin{array}{l}1 /\{k\} \\
7.242924(61) \times 10^{22}\end{array}$ & $\begin{array}{l}1 /\{e\} \\
6.2415064(19) \times 10^{18}\end{array}$ & $\begin{array}{l}1 /\left\{m_{\mathrm{u}} c^{2}\right\} \\
6.7005308(40) \times 10^{9}\end{array}$ & $\begin{array}{l}1 /\left\{2 R_{\infty} h c\right\} \\
2.2937104(14) \times 10^{17}\end{array}$ \\
\hline $1 \mathrm{~kg}=$ & $\begin{array}{l}\left\{c^{2} / k\right\} \\
6.509616(55) \times 10^{39}\end{array}$ & $\begin{array}{l}\left\{c^{2} / e\right\} \\
5.6095862(17) \times 10^{35}\end{array}$ & $\begin{array}{l}1 /\left\{m_{\mathrm{u}}\right\} \\
6.0221367(36) \times 10^{26}\end{array}$ & $\begin{array}{l}\left\{c / 2 R_{\infty} h\right\} \\
2.0614841(12) \times 10^{34}\end{array}$ \\
\hline $1 \mathrm{~m}^{-1}=$ & $\begin{array}{l}\{h c / k\} \\
0.01438769(12)\end{array}$ & $\begin{array}{l}\{h c / e\} \\
1.23984244(37) \times 10^{-6}\end{array}$ & $\begin{array}{l}\left\{h / m_{\mathrm{u}} c\right\} \\
1.33102522(12) \times 10^{-15}\end{array}$ & $\begin{array}{l}1 /\left\{2 R_{\infty}\right\} \\
4.5563352672(54) \times 10^{-8}\end{array}$ \\
\hline $1 \mathrm{~Hz}=$ & $\begin{array}{l}\{h / k\} \\
4.799216(41) \times 10^{-11}\end{array}$ & $\begin{array}{l}\{h / e\} \\
4.1356692(12) \times 10^{-15}\end{array}$ & $\begin{array}{l}\left\{h / m_{\mathrm{u}} c^{2}\right\} \\
4.43982224(40) \times 10^{-24}\end{array}$ & $\begin{array}{l}1 /\left\{2 R_{\infty} c\right\} \\
1.5198298508(18) \times 10^{-16}\end{array}$ \\
\hline $1 \mathrm{~K}=$ & 1 & $\begin{array}{l}\{k / e\} \\
8.617385(73) \times 10^{-5}\end{array}$ & $\begin{array}{l}\left\{k / m_{\mathrm{u}} c^{2}\right\} \\
9.251140(78) \times 10^{-14}\end{array}$ & $\begin{array}{l}\left\{k / 2 R_{\infty} h c\right\} \\
3.166829(27) \times 10^{-6}\end{array}$ \\
\hline $1 \mathrm{eV}=$ & $\begin{array}{l}\{e / k\} \\
11604.45(10)\end{array}$ & 1 & $\begin{array}{l}\left\{e / m_{\mathrm{u}} c^{2}\right\} \\
1.07354385(33) \times 10^{-9}\end{array}$ & $\begin{array}{l}\left\{e / 2 R_{\infty} h c\right\} \\
0.036749309(11)\end{array}$ \\
\hline $1 u=$ & $\begin{array}{l}\left\{m_{\mathrm{u}} c^{2} / k\right\} \\
1.0809478(91) \times 10^{13}\end{array}$ & $\begin{array}{l}\left\{m_{\mathrm{u}} c^{2} / e\right\} \\
931.49432(28) \times 10^{6}\end{array}$ & 1 & $\begin{array}{l}\left\{m_{\mathrm{u}} c / 2 R_{\infty} h\right\} \\
3.42317725(31) \times 10^{7}\end{array}$ \\
\hline ee $=$ & $\begin{array}{l}\left\{2 R_{\infty} h c / k\right\} \\
3.157733(27) \times 10^{5}\end{array}$ & $\begin{array}{l}\left\{2 R_{\infty} h c / e\right\} \\
27.2113961(81)\end{array}$ & $\begin{array}{l}\left\{2 R_{\infty} h / m_{\mathrm{u}} c\right\} \\
2.92126269(26) \times 10^{-8}\end{array}$ & 1 \\
\hline
\end{tabular}


Table 5. Expanded covariance and correlation coefficient matrix for the 1986 recommended set of fundamental physical constants.

The elements of the covariance matrix appear on and above the major diagonal in (parts in $\left.10^{9}\right)^{2}$; correlation coefficients appear in italics below the diagonal. The values are given to as many as six digits only as a matter of consistency.

The correlation coefficient between $m_{c}$ and $N_{\mathrm{A}}$ appears as -1.000 in this table because the auxiliary constants were considered to be exact in carrying out the least-squares adjustment. When the uncertainties of $m_{\mathrm{p}} / m_{\mathrm{e}}$ and $M_{\mathrm{p}}$ are properly taken into account, the correlation coefficient is -0.999 and the variances of $m_{\mathrm{e}}$ and $N_{\mathrm{A}}$ are slightly increased.

\begin{tabular}{|c|c|c|c|c|c|c|c|c|c|}
\hline & $\alpha^{-1}$ & $K_{\mathbf{v}}$ & $K_{\Omega}$ & $\mu_{\mu} / \mu_{p}$ & $e$ & $h$ & $m_{\mathrm{e}}$ & $N_{\mathrm{A}}$ & $F$ \\
\hline$\alpha^{-1}$ & 1997 & -1062 & 925 & 3267 & -3059 & -4121 & -127 & 127 & -2932 \\
\hline$K_{\mathbf{v}}$ & -0.080 & 87988 & 90 & -1737 & 89050 & 177038 & 174914 & -174914 & -85864 \\
\hline$K_{\Omega}$ & 0.416 & 0.006 & 2477 & 1513 & -835 & -744 & 1105 & -1105 & -1939 \\
\hline$\mu_{\mu} / \mu_{p}$ & 0.498 & -0.040 & 0.207 & 21523 & -5004 & -6742 & -208 & 208 & -4796 \\
\hline$e$ & -0.226 & 0.989 & -0.055 & -0.112 & 92109 & 181159 & 175042 & -175042 & -82933 \\
\hline$h$ & -0.154 & 0.997 & -0.025 & -0.077 & 0.997 & 358197 & 349956 & -349956 & -168797 \\
\hline$m_{e}$ & -0.005 & 0.997 & 0.038 & -0.002 & 0.975 & 0.989 & 349702 & -349702 & -174660 \\
\hline$N_{\mathrm{A}}$ & 0.005 & -0.997 & -0.098 & 0.002 & -0.975 & -0.989 & -1.000 & 349702 & 174660 \\
\hline$F$ & -0.217 & -0.956 & -0.129 & -0.108 & -0.902 & -0.931 & -0.975 & 0.975 & 91727 \\
\hline
\end{tabular}

involving the fundamental constants, the variables $x_{i}$ may be taken to be the fractional change in the physical quantity from some fiducial value, and the quantities $Q$ can be expressed as powers of physical constants $Z_{j}$ according to

$$
Q_{k}=q \prod_{j=1}^{N} Z_{j}^{Y_{k j}},
$$

where $q$ is a numerical factor. If the variances and covariances are then expressed in relative units, eq (1) becomes

$$
v_{k s}=\sum_{i, j=1}^{N} Y_{k i} Y_{s j} v_{i j},
$$

where the $v_{i j}$ are to be expressed, for example, in (parts in $\left.10^{9}\right)^{2}$. Equation (3) is the basis for the expansion of the covariance matrix to include $e, h$, $m_{e}, N_{\mathrm{A}}$, and $F$.

In terms of correlation coefficients defined by $r_{i j} \equiv v_{i j}\left(v_{i i} v_{j j}\right)^{-1 / 2} \equiv v_{i j} / \epsilon_{i} \epsilon_{j}$, where $\epsilon_{i}$ is the standard deviation $\left(\epsilon_{i}^{2}=v_{i i}\right)$, we may write, from eq (3),

$$
\epsilon_{k}^{2}=\sum_{i=1}^{N} Y_{k i}^{2} \epsilon_{i}^{2}+2 \sum_{j<i}^{N} Y_{k i} Y_{k j} r_{i j} \epsilon_{i} \epsilon_{j},
$$

where the standard deviations are to be expressed in relative units.

As an example of the use of table 5, consider the calculation of the uncertainty of the Bohr magneton $\mu_{\mathrm{B}}=e h / 2 m_{\mathrm{e}}(\hbar=h / 2 \pi)$. In terms of the variables of the 1986 adjustment this ratio is given by

$$
\mu_{\mathrm{B}}=\left[2 \pi \mu_{0} R_{\infty} E\right]^{-1}\left(\alpha^{-1}\right)^{-3} K_{\mathrm{V}},
$$

where the quantities in brackets are auxiliary constants taken to be exact. Using eq (3) and letting $\alpha^{-1}$ correspond to $i=1$ and $K_{\mathrm{V}}$ to $i=2$ gives $^{5}$

$$
\epsilon_{\mu_{\mathrm{B}}}^{2}=Y_{1}^{2} v_{11}+2 Y_{1} Y_{2} v_{12}+Y_{2}^{2} v_{22}
$$

Comparing eq (5) with eq (2) yields $Y_{1}=-3$ and $Y_{2}=1$. Thus eq (6) and table 5 lead to

$$
\epsilon_{\mu_{B}}^{2}=[9(1997)-6(-1062)+1(87988)] \times\left(10^{-9}\right)^{2}
$$

or $\epsilon_{\mu_{\mathrm{B}}}=0.335 \mathrm{ppm}$. An alternate approach is to evaluate $e \hbar / 2 m_{\mathrm{e}}$ directly from table 5; then $e$ corresponds to $i=5, h$ to $i=6$, and $m_{\mathrm{e}}$ to $i=7$ with $Y_{5}=Y_{6}=1$ and $Y_{7}=-1$. Then

$$
\begin{aligned}
\epsilon_{\mu_{\mathrm{B}}}^{2}= & Y_{5}^{2} v_{55}+2 Y_{5} Y_{6} v_{56}+Y_{6}^{2} v_{66} \\
& +2 Y_{5} Y_{7} v_{57}+2 Y_{6} Y_{7} v_{67}+Y_{7}^{2} v_{77} \\
= & {[1(92109)+2(181159)+1(358197)} \\
& -2(175042)-2(349956) \\
& +1(349702)] \times\left(10^{-9}\right)^{2}
\end{aligned}
$$

which also yields $\epsilon_{\mu_{\mathrm{B}}}=0.335 \mathrm{ppm}$.

\footnotetext{
${ }^{5}$ Note that in using eq (3), we set $s=k, \epsilon_{k}^{2}=v_{k k}$, suppress $k$ as a subscript on $Y$, and replace $k$ with $\mu_{\mathrm{B}}$.
} 


\section{References}

[1] Cohen, E. R., and B. N. Taylor, The 1986 Adjustment of the Fundamental Physical Constants, a Report of the CODATA Task Group on Fundamental Constants, CODATA Bulletin 63, Pergamon Press: Maxwell House, Fairview Park, Elmsford, NY, 10523, or Headington Hill Hall, Oxford OX3 OBW, U.K. (November, 1986).

[2] Recommended Consistent Values of the Fundamental Physical Constants, 1973, a Report of the CODATA Task Group on Fundamental Constants, CODATA Bulletin 11, CODATA Secretariat, 51 Blvd. de Monmorency, 75016 Paris, France (August, 1973).

[3] Cohen, E. R., and B. N. Taylor, J. Phys. Chem. Ref. Data 2663 (1973).

[4] Taylor, B. N.; W. H. Parker and D. N. Langenberg, Rev. Mod. Phys. 41375 (1969); also published as The Fundamental Constants and Quantum Electrodynamics, Academic Press: New York (1969).

[5] Cohen, E. R., and J. W. M. DuMond, Rev. Mod. Phys. 37 537 (1965).

[6] Com. Intl. Poids Mes. Com. Consult. d'Electricité, Trav. $13^{\mathrm{e}}$ Session (Bur. Intl. Poids Mes., Sèvres, France, Oct. 1972), p. E 13; Terrien, J., Metrologia 940 (1973).

[7] P. V. Séances Com. Intl. Poids Mes., $61^{\mathrm{e}}$ Session, 40 (Bur. Intl. Poids Mes., Sèvres, France, Oct. 1972), pp. 22, 100.

[8] Taylor, B. N., J. Res. Natl. Bur. Stand. 91299 (1986).

[9] Taylor, B. N., J. Res. Natl. Bur. Stand. 9255 (1987). 